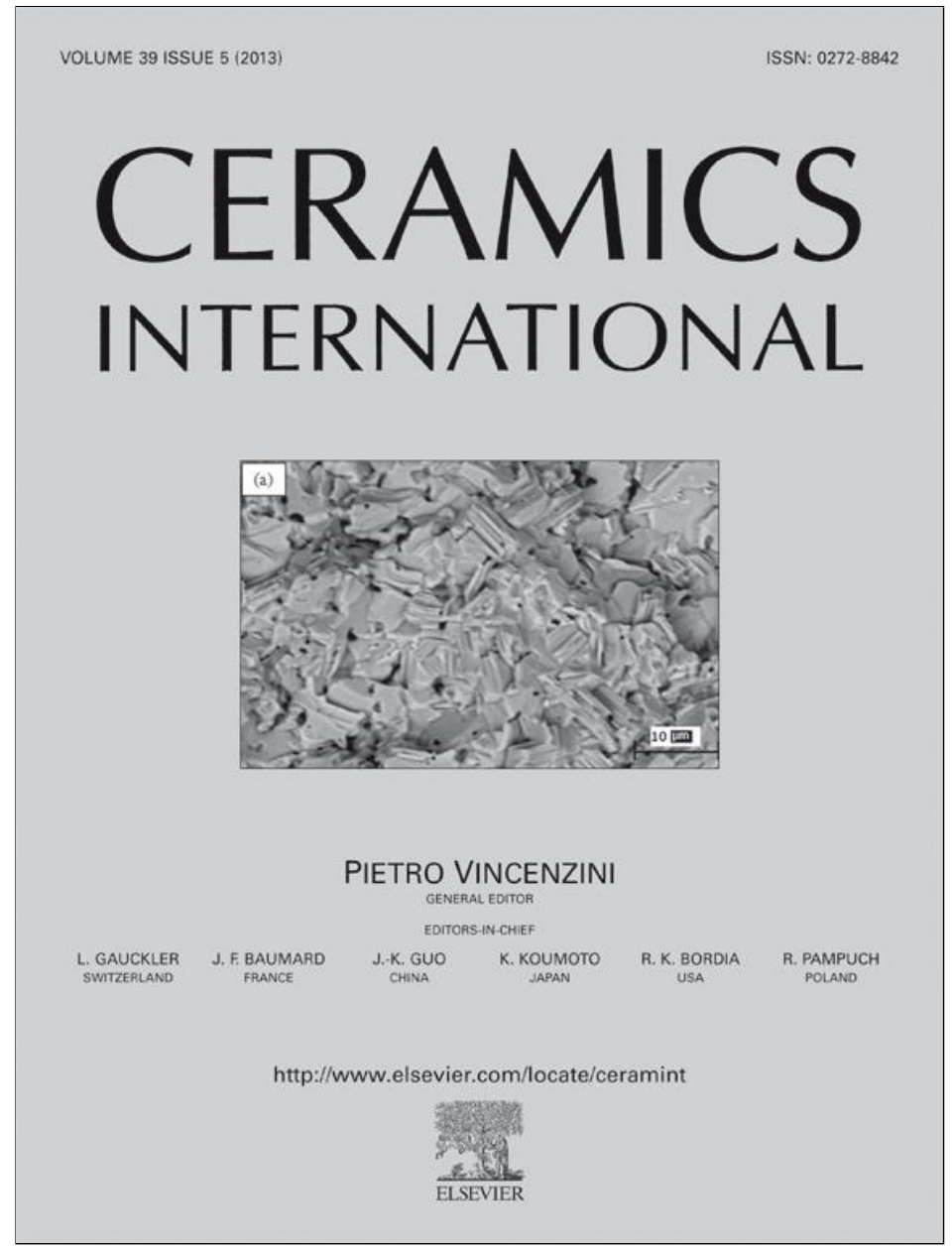

This article appeared in a journal published by Elsevier. The attached copy is furnished to the author for internal non-commercial research and education use, including for instruction at the authors institution and sharing with colleagues.

Other uses, including reproduction and distribution, or selling or licensing copies, or posting to personal, institutional or third party websites are prohibited.

In most cases authors are permitted to post their version of the article (e.g. in Word or Tex form) to their personal website or institutional repository. Authors requiring further information regarding Elsevier's archiving and manuscript policies are encouraged to visit:

http://www.elsevier.com/authorsrights 


\title{
Phase stabilization in plasma sprayed $\mathrm{BaTiO}_{3}$
}

\author{
P. Ctibor ${ }^{\mathrm{a},},{ }^{*}$ H. Seiner ${ }^{\mathrm{b}}$, J. Sedlacek ${ }^{\mathrm{c}}$, Z. Pala ${ }^{\mathrm{a}}$, P. Vanek ${ }^{\mathrm{d}}$ \\ anstitute of Plasma Physics, AS CR, v.v.i., Za Slovankou 3, 18200 Praha 8, Czech Republic \\ ${ }^{\mathrm{b}}$ Institute of Thermomechanics, AS CR, v.v.i., Dolejskova 5, 18200 Praha 8, Czech Republic \\ ${ }^{\mathrm{c}}$ Department of Electrotechnology, Faculty of Electrical Engineering, Czech Technical University, Technicka 2, Praha 6, Czech Republic \\ ${ }^{\mathrm{d}}$ Institute of Physics, AS CR, v.v.i., Na Slovance 2, 18221 Praha 8, Czech Republic
}

Received 19 September 2012; received in revised form 28 November 2012; accepted 30 November 2012

Available online 10 December 2012

\begin{abstract}
This paper presents a comparison of properties of $\mathrm{BaTiO}_{3}$ ceramics prepared by two different production methods: gas-stabilized plasma spraying (GSP) and spark plasma sintering (SPS). Samples of both materials were evaluated by various techniques, the goal being to detect the Curie temperature of the ferroelectric transformation between the tetragonal and the cubic phase. All tests, resonant ultrasound spectroscopy, dielectric measurements, differential scanning calorimetry and temperature-resolved X-ray diffraction (XRD), used in combination, proved the absence of this transformation in the case of GSP coating up to $500{ }^{\circ} \mathrm{C}$. Similarly, the tetragonal-toorthorhombic transition temperature is shifted downwards, this transition probably taking place in a small fraction of the volume of coating. The SPS samples exhibit several anomalies, such as a strong anisotropy of relative permittivity, but their phase transformations were detected in the usual temperature ranges.
\end{abstract}

(c) 2012 Elsevier Ltd and Techna Group S.r.l. All rights reserved.

Keywords: B. Spectroscopy; D. $\mathrm{BaTiO}_{3}$; Plasma spraying; Spark plasma sintering

\section{Introduction}

Enhanced piezoelectricity in lead-free ceramics is of great interest for human health and environmental protection. In recent times, the development of lead-free piezoelectric ceramics with excellent properties has been investigated to find an alternative for toxic lead zirconate titanate (PZT). Among the candidates, barium titanate $\left(\mathrm{BaTiO}_{3}\right.$, labeled BT), which is currently used as a dielectric material for capacitor application, was actually lead-free and the first material practically used to prepare piezoelectric ceramics before the discovery of a highperformance PZT. Although $\mathrm{BaTiO}_{3}$ ceramics have been reported to have a moderate piezoelectric performance for several decades, recent studies revealed that highperformance BT ceramics can be obtained [1].

$\mathrm{BaTiO}_{3}$ is an interesting multifunctional oxide that exhibits a complex phase appearance. Between $120^{\circ} \mathrm{C}$ $(393 \mathrm{~K})$ and $1457^{\circ} \mathrm{C}(1730 \mathrm{~K}), \mathrm{BaTiO}_{3}$ has a cubic perovskite

\footnotetext{
${ }^{*}$ Corresponding author. Tel.: +420 266053717; fax: +420 28586389 .

E-mail address: ctibor@ipp.cas.cz (P. Ctibor).
}

structure that consists of corner linked oxygen octahedra containing $\mathrm{Ti}^{4+}$, with $\mathrm{Ba}^{2+}$. Cooling below $120{ }^{\circ} \mathrm{C}$ results in small displacements in the positions of the cations in the unit cell resulting in the tetragonal polar ferroelectric phase existing in the temperature interval between $5{ }^{\circ} \mathrm{C}(278 \mathrm{~K})$ and $120{ }^{\circ} \mathrm{C}$ [2].

In general, there are differences in the behavior of barium titanate in the form of a single crystal, sintered bulk material, thin film and spark plasma sintered disks [2-4]. Plasma spraying enables creation of layers with "bulk-like" thickness but adhering to a metallic substrate of various shapes. Freestanding parts of titanate ceramics can be fabricated as well by plasma spraying [5]. Until now, $\mathrm{BaTiO}_{3}$ itself was rarely plasma sprayed and the understanding of its behavior in the form of sprayed coating is not satisfactory. For coatings with the thickness of about $100 \mu \mathrm{m}$, the values of relative permittivity 50 and loss factor 0.08 were reported [6]. The dielectric properties of the plasma sprayed $\mathrm{BaTiO}_{3}$ were related to the degree of crystallinity. The coatings containing more crystalline material have higher relative permittivity. The relative permittivity was affected also by cracks and splat interfaces within the coating [6]. The reported value of relative 
permittivity is, however, surprisingly low because one or more orders higher values are typical for bulk $\mathrm{BaTiO}_{3}$ [7].

The spark plasma sintering (SPS) system was developed in 1990s. It is a process that uses microscopic electrical discharges between particles under pressure. Hence, it is a combination of a hot-press and an electric power generator [8]. The conventional procedures as classical liquid phase sintering, however, reached their limits in the preparation of fine-grained materials, especially because of relatively long sintering times in combination with high temperatures which are necessary for the sintering of compact fully dense materials. The problems of long sintering times are significantly reduced using the SPS technique [9]. The sintered material is surrounded by graphite elements for application of heating and for obtaining the desirable form. Therefore, rather than just simple shapes such as tablets, cylinders and small axially symmetrical bodies could be manufactured by SPS.

$\mathrm{BaTiO}_{3}$ with different grain size ranging from $80 \mathrm{~nm}$ to several micrometers were prepared by controlling sintering conditions at the SPS process [8]. Investigation of the grain size dependence of dielectric properties shows that the relative permittivity at room temperature decreased with the diminishing grain size - from 4000 for $1 \mu \mathrm{m}$ grain size to about 1500 for $100 \mathrm{~nm}$ grain size. The SPS process, when operated under a reducing atmosphere, is able to create such defects as $\mathrm{Ti}^{3+}$ associated with oxygen vacancies [10].

The applicability of $\mathrm{BaTiO}_{3}$ as a bulk piezoelectric material is limited to a temperature range of the stability of the polar ferroelectric phase, i.e., between approximately $5{ }^{\circ} \mathrm{C}$ (the tetragonal-to-orthorhombic transition temperature) and $120{ }^{\circ} \mathrm{C}$ (the cubic-to-tetragonal t.t.). The upper limit can be shifted by aging to above $130{ }^{\circ} \mathrm{C}$ [11]. Even stronger stabilization of the tetragonal phase (nearly to $150{ }^{\circ} \mathrm{C}$ ) was observed for nanoceramic $\mathrm{BaTiO}_{3}$ prepared by low temperature high pressure (LTHP) sintering $[12,13]$. However, these shifts of the Curie point are small compared with the stabilization effect taking place in thin $\mathrm{BaTiO}_{3}$ layers grown epitaxially on rare-earth scandate substrates [14,15], for which the tetragonal phase remains stable up to $600{ }^{\circ} \mathrm{C}$.

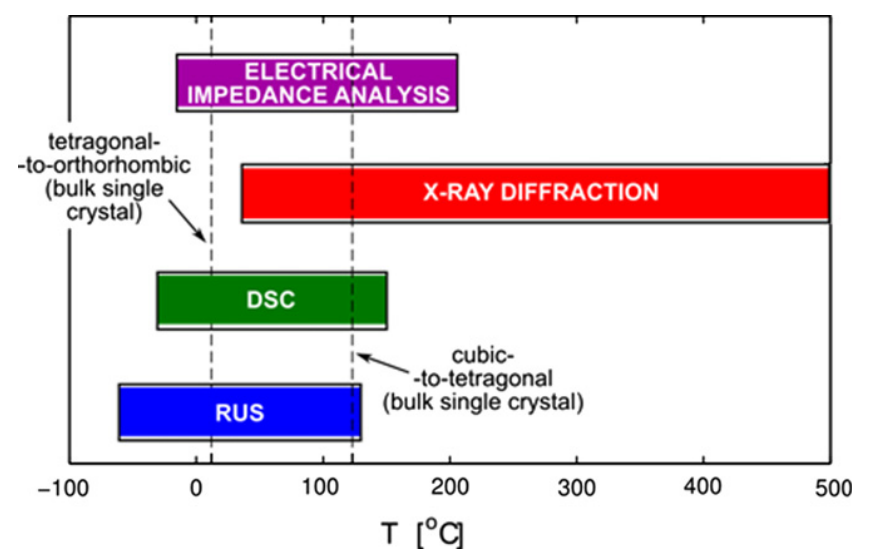

Fig. 1. Temperature intervals applied for various testing methods used.
The goal of the present paper is to compare selected properties of the plasma sprayed BT coating and SPS bulk BT material. The main attention is on the examination of the relations between polar tetragonal structure and the nonpolar cubic perovskite structure of BT. When necessary, the untreated starting powder is also compared as a reference. For improved clarity, the temperature intervals applied for each test are summarized in Fig. 1.

\section{Experimental}

\subsection{Material and specimen preparation}

BT feedstock powder was obtained by crushing and sieving sintered coarse agglomerates. Those agglomerates were prepared by a reactive sintering of micrometer-sized powders of $\mathrm{BaCO}_{3}$ and $\mathrm{TiO}_{2}$ used as starting materials. After sieving the feedstock, the size distribution was between 20 and $63 \mu \mathrm{m}$ with an average at $40 \mu \mathrm{m}$, whereas its bulk density measured by helium pycnometry was $5725 \pm 1 \mathrm{~kg} \mathrm{~m}^{-3}$.

A gas-stabilized plasma (GSP) gun was used to perform atmospheric plasma spraying (APS) of the BT feedstock. The conventional direct-current GSP gun F4 (SulzerMetco, Wohlen, Switzerland) was equipped with a thoriated tungsten cathode. The plasma gas mixture used was argon/hydrogen with flow rates of $45 / 15$ standard liters per minute $(\mathrm{slm})$ or $53 / 7 \mathrm{slm}$. The powder was injected perpendicularly to the plasma jet axis with argon as a carrier gas through an injector located $3 \mathrm{~mm}$ downstream (called external injection) of the torch nozzle exit. The system can process 1 to $5 \mathrm{~kg} / \mathrm{h}$ of a ceramic powder. BT was sprayed at arc power of around $30 \mathrm{~kW}$ because the feedstock was coarser than reported in the work [16], describing an as-sprayed $\mathrm{BaTiO}_{3}$ microstructure as predominantly amorphous when the torch power was $37.8 \mathrm{~kW}$. The goal of using lower power in our experiments was to minimize overheating and associated amorphization. Spray distance was between 100 and $150 \mathrm{~mm}$. Plasma spraying deposition time was 5 min to reach the thickness about $0.9 \mathrm{~mm}$. Substrates were $3 \mathrm{~mm}$ thick, made of carbon steel, and grit blasted before spraying to coarsen its surface. The resulting substrate roughness was $R_{\mathrm{a}}=5.6 \pm 0.3 \mu \mathrm{m}$. Then substrates were cleaned in acetone in an ultrasonic bath. The bulk density of the coating measured by helium pycnometry was $5365 \pm 1 \mathrm{~kg} \mathrm{~m}^{-3}$ (i.e. $93.7 \%$ of the powder density).

At the SPS process on FCT HP D 25/1 device (FCT Systeme GmbH, Rauenstein, Germany), the sintering temperature $1300{ }^{\circ} \mathrm{C}$, heating rate $165^{\circ} \mathrm{C} / \mathrm{min}$, pressure $80 \mathrm{MPa}$, sintering time $20 \mathrm{~min}$ and controlled cooling with the cooling rate of $100{ }^{\circ} \mathrm{C} / \mathrm{min}$ were applied. Maximum shrinkage rate $2.3 \mathrm{~mm} / \mathrm{min}$ was detected at $1250{ }^{\circ} \mathrm{C}$. The pressure in the sintering chamber was reduced (i.e., no protective gas was used). The bulk density of the sintered disc measured by helium pycnometry was $5663 \pm 1 \mathrm{~kg} \mathrm{~m}^{-3}$ (i.e. $98.3 \%$ of the powder density). 


\subsection{Resonant ultrasound spectroscopy}

Resonant ultrasound spectroscopy (RUS) [17-20] was applied to monitor changes of elastic properties of the SPS and GSP $\mathrm{BaTiO}_{3}$ materials with temperature. For the SPS material, the used specimen was a rectangular $1.32 \times 2.10 \times 3.77 \mathrm{~mm}^{3}$ parallelepiped. For the GSP material, a sandwich-like specimen was prepared consisting of a $0.75 \mathrm{~mm}$ thick steel substrate and $0.83 \mathrm{~mm}$ thick GSP coating. This geometry was chosen since the GSP coating itself has a very high mechanical damping and hence, a sample of a freestanding coating would not be suitable for the RUS measurements. The presence of the steel substrate resulted in a significant decrease of the average mechanical damping in the specimen that enabled the RUS method to be applied. It was assumed that the material of the substrate (common carbon steel) does not exhibit any pronounced changes in elastic moduli or in damping in the given temperature range. This means that the resulting evolution of the resonant spectrum with temperature can be fully ascribed to the evolution of mechanical properties of the coating. The lateral dimensions of this specimen were $3.31 \times 2.25 \mathrm{~mm}^{2}$.

The resonant spectra of these two specimens were measured during the same thermal cycle: starting from $+130{ }^{\circ} \mathrm{C}$, cooling down $-60{ }^{\circ} \mathrm{C}$, and finally heating up back to $+130{ }^{\circ} \mathrm{C}$, with a temperature step of $2-10{ }^{\circ} \mathrm{C}$ (finer resolution close to the expected transition temperatures). The measurements were performed in a fully non-contact regime, using lasers both for the generation and detection of the vibrations [20]. For this generation, sequences of pulses of a focused infrared laser beam (pulse duration $8 \mathrm{~ns}$, energy $25 \mathrm{~mJ}$, Quantel ULTRA Nd:YAG laser system, equipped with fiber optic) were used. The displacement response was detected by a Polytec Micro System Analyzer MSA-500 (using an OFV-5000 controller and an OFV-551 sensor head). For each temperature, the response was measured in 13 different points covering one face of the specimen so as to obtain an average spectrum sufficiently representing the vibrations of the whole volume.

For both specimens, the resonant spectra were obtained in a frequency range of $10 \mathrm{kHz}$ to $100 \mathrm{kHz}$, which covered the first 4 detectable modes for the SPS material and first 6 detectable modes for the GSP material. As usual when the RUS method is applied to detect the transition temperatures [21,22], the spectra were not used for the calculation of the exact values of the elastic constants, but one dominant peak was chosen and followed throughout the whole temperature range. For each temperature, this peak was fitted by a Gaussian mask, and the position of its maximum and the corresponding internal friction factor $\left(Q^{-1}\right)$ were determined. As mentioned in Ref. [21], the temperature dependence of the position of such a peak corresponds well to the temperature dependence of the shear modulus $G$, at least for isotropic or nearly isotropic materials. Similarly, the obtained temperature dependence of the factor can be expected to follow the temperature dependence of shear viscosity of the material (the complex part of $G$ ). For both specimens, the behavior of the chosen peak in the whole temperature range was checked that it is the same (or very similar) to the behaviors of all peaks in the measured part of the spectrum.

\subsection{X-ray diffraction}

To pinpoint structural changes brought about by heating the GSP coating and the SPS bulk sample, they were subjected to phase analyses by X-ray diffraction. Parameters of the diffraction measurements with X'Pert PRO multi-purpose diffractometer and $\operatorname{CoK} \alpha$ radiation were as follows: $2 \theta$ range from $20^{\circ}$ to $120^{\circ}$, step size $0.067^{\circ} 2 \theta$, counting time $250 \mathrm{~s}$, beta filter made from an iron thin sheet placed in front of a fast RTMS (real time multiple strip) detector. The samples, measured in standard BraggBrentano geometry, were kept in vacuum in a high temperature chamber with kapton windows. The temperature of the heat strip made from platinum was set to 100 , 200, 300, 400, and $500{ }^{\circ} \mathrm{C}$. The temperature of the Pt heat strip usually does not precisely match the temperature of the measured surface. Hence, the diffraction peaks from the $\alpha$-Fe from the steel substrate for the GSP coating were used for lattice parameter refinement and following temperature calculation according to the law of thermal expansion. Since the temperature corrections were in the range $2-6{ }^{\circ} \mathrm{C}$, we have abstained from it and the individual diffraction patterns are denoted by the temperature of the Pt heat strip.

\subsection{Electric measurements}

Electric measurements of the plasma sprayed coatings were performed after removing the coatings from the metallic substrate. The surface of specimens was made smooth to eliminate surface roughness. Layers of aluminum as thin film electrodes were sputtered in a reduced pressure on both sides of each sample. A three-electrode measurement fixture was used to evaluate dielectric parameters of GSP samples. A test fixture was inserted in a calibration cell of the temperature calibrator Isotech Venus 2140 apparatus working in a temperature ranging from $-55^{\circ} \mathrm{C}$ to $+140{ }^{\circ} \mathrm{C}$. The electric field was applied parallel to the spraying direction (i.e., perpendicular to the substrate surface).

Electric measurements of the SPS samples were performed on rectangular samples $2 \times 5 \times 12 \mathrm{~mm}^{3}$ cut from the as-sintered cylindrical tablet. Grinding and sputtering was the same as for the plasma sprayed samples. The electric field was applied perpendicularly to the sintering pressure direction as well as parallel with it. Capacity at room temperature of both — SPS and plasma sprayed samples - was measured in the frequency range of from $9 \mathrm{kHz}$ to $1 \mathrm{MHz}$ using a programmable impedance analyzer model PM6306 (Fluke, the Netherlands). Applied voltage was $1 \mathrm{~V}$ AC. Relative permittivity $\varepsilon_{\mathrm{r}}$ was calculated 
from measured capacities $C_{\mathrm{P}}$ and specimen dimensions. This same arrangement and equipment was used for the loss tangent measurement at the same frequencies as capacity.

Electric resistance was measured with a special resistivity adapter - Keithley model 6105. The DC electric field was applied from a regulated high-voltage source and the values were read by a multi-purpose electrometer (617C, Keithley Instruments, USA). The magnitude of the applied voltage was $100 \pm 2 \mathrm{~V}$. Volume resistivity was calculated from the measured resistance and specimen dimensions. Three specimens were measured and the average was calculated.

\subsection{Differential scanning calorimetry (DSC)}

Thermodynamic parameters of the phase transitions were determined by a PerkinElmer Pyris Diamond DSC differential scanning calorimeter. The temperature range from -40 to $+150{ }^{\circ} \mathrm{C}$ was used, the scanning rate $10 \mathrm{~K} / \mathrm{min}$, nitrogen atmosphere, samples ( $m=10$ to $100 \mathrm{mg}$ ) in $\mathrm{Al}$ pans, temperature and enthalpy calibration on the extrapolated onsets and enthalpy of melting, respectively, of water, indium and zinc.

\section{Results}

\subsection{Resonant ultrasound spectroscopy}

Fig. 2 shows the temperature dependence of the resonant frequency of the chosen mode and the corresponding damping for the SPS material. The frequency is normalized to its value at room temperature (RT) during the heating run $\left(f_{\mathrm{RT}}\right)$. It is clearly seen that the material undergoes two, well detectable phase transitions. At approximately $+120{ }^{\circ} \mathrm{C}$, the slope of the $f(T)$ curve abruptly changes and this change is followed by a broad, but well pronounced peak on the $Q^{-1}(T)$ curve. This temperature

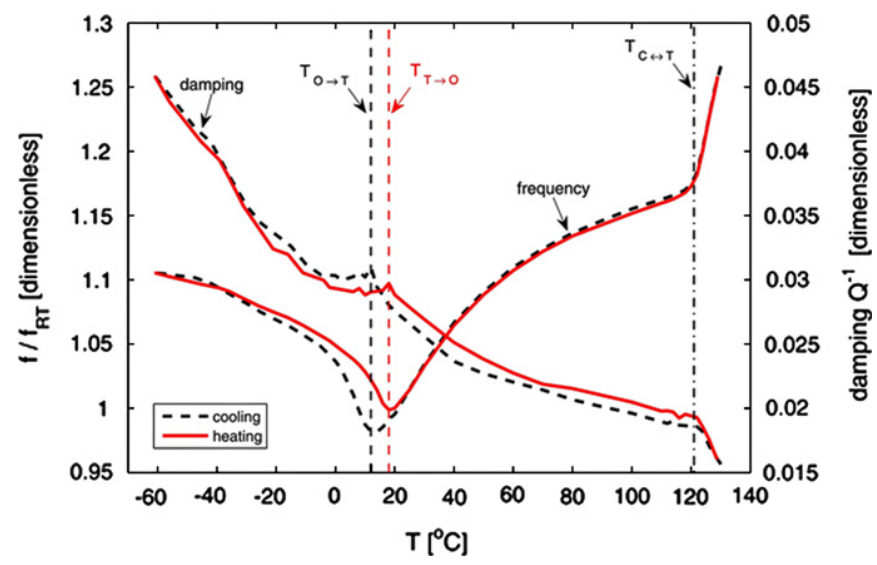

Fig. 2. Temperature dependence of the frequency of a chosen mode from the RUS spectrum (left vertical axis) and of the corresponding damping (right vertical axis) for the SPS material. Dashed and dash-dotted vertical lines denote the temperatures of individual phase transitions. corresponds perfectly to the theoretically predicted temperature for the cubic-to-tetragonal (ferroelectric) transition. As expected for a ferroelectric transition, no temperature hysteresis can be observed.

The second abrupt change of the $f(T)$ slope appears at $+12{ }^{\circ} \mathrm{C}$ during cooling and at $+18{ }^{\circ} \mathrm{C}$ during heating. These changes correspond to the tetragonal-toorthorhombic transition for cooling and the reverse (orthorhombic-to-tetragonal) transition for heating. Below $+18{ }^{\circ} \mathrm{C}$, a hysteretic loop is formed, and both curves overlap again approximately at $-40{ }^{\circ} \mathrm{C}$. This indicates that either the tetragonal-to-orthorhombic transition starts at $+12{ }^{\circ} \mathrm{C}$ but is not fully completed until $-40{ }^{\circ} \mathrm{C}$, or that the tetragonal-to-orthorhombic transition induces some defects or other microstructural features which are fully relaxed at $-40{ }^{\circ} \mathrm{C}$, but do not reappear during heating. The $f(T)$ curves perfectly overlap above $+18^{\circ} \mathrm{C}$, which means that the reverse transition is fully completed above this temperature. The slope changes of $f(T)$ at $+12{ }^{\circ} \mathrm{C}$ and $+18{ }^{\circ} \mathrm{C}$ are also easily followed by two sharp peaks on the $Q^{-1}(T)$ curve. Between the cubic-to-tetragonal and the tetragonal-to-orthorhombic transition, the $f(T)$ curve is continuously increasing and strictly concave. This anomalous behavior can be explained by the instability of the tetragonal lattice and its further softening towards the tetragonal-to-orthorhombic transition temperature.

Fig. 3 shows the results of the RUS measurement for the sandwich-like specimen of the GSP coating. It can be clearly seen that the temperature dependencies of both the frequency and the damping are completely different than in the case of the SPS material. Most importantly, there is no significant slope change at the $f(T)$ curve and no damping peak close to $+120^{\circ} \mathrm{C}$. Instead, a broad maximum of the damping appears approximately at $+85^{\circ} \mathrm{C}$. Below this temperature, the damping steeply decreases until RT, where the value of $Q^{-1}$ is about 10 times smaller than the maximum.

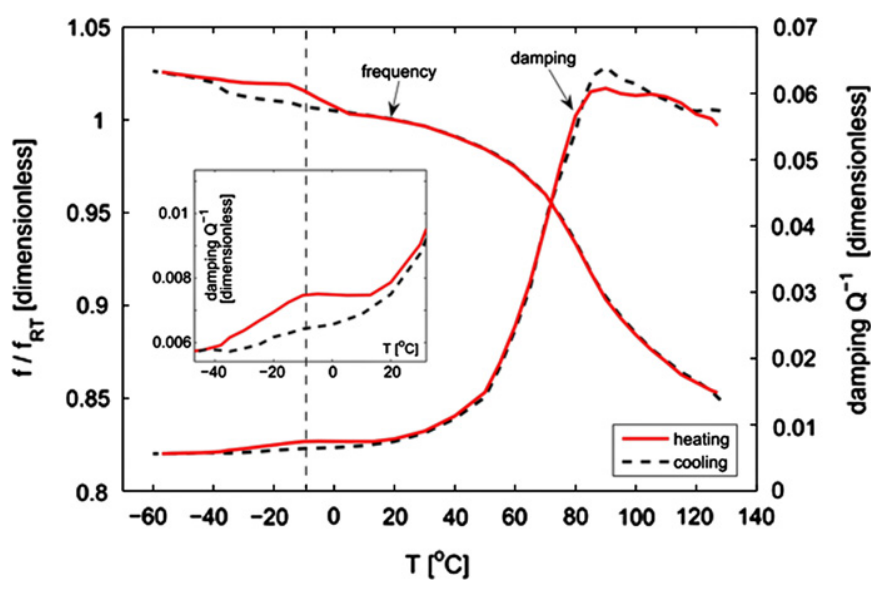

Fig. 3. Temperature dependence of the frequency of the chosen mode from the RUS spectrum (left vertical axis) and of the corresponding damping (right vertical axis) for the GSP coating. The zoomed area shows the damping peak corresponding to the reverse structural transition in low temperatures. 


\subsection{X-ray diffraction}

The phase evolution of the SPS material (Fig. 4 - top) detected by XRD is conventional - tetragonal BT phase P4mm (PDF2 Card no. 01-081-2204) exists at $100{ }^{\circ} \mathrm{C}$ and cubic phase at all three higher temperatures. The transformation is demonstrated in Fig. 4 on the change of the character of peaks corresponding to $\{002\},\{200\}$ and $\{220\}$ planes. The situation is different regarding the plasma sprayed coating (Fig. 4 - bottom). The peaks corresponding to $\alpha$-Fe from the steel substrate are close to the observed peaks of BT. However, at both $2 \theta$ positions (at $52^{\circ}$ and $78^{\circ}$ ) a single peak is present, corresponding to $\{200\}$ and $\{220\}$ planes in cubic $\mathrm{BaTiO}_{3}$, respectively.

\subsection{Electric measurements}

Fig. 5 shows the relative permittivity measurement results for the GSP coating. The dependence of permittivity on temperature exhibits a maximum at $200{ }^{\circ} \mathrm{C}$, which was the highest measured temperature. This temperature is $75{ }^{\circ} \mathrm{C}$ above the theoretical temperature of the $\mathrm{t}-\mathrm{c}$ phase transformation. At all frequencies [23,24] there is a monotonous increase of the permittivity with temperature. The permittivity values exhibit a pronounced increase when the
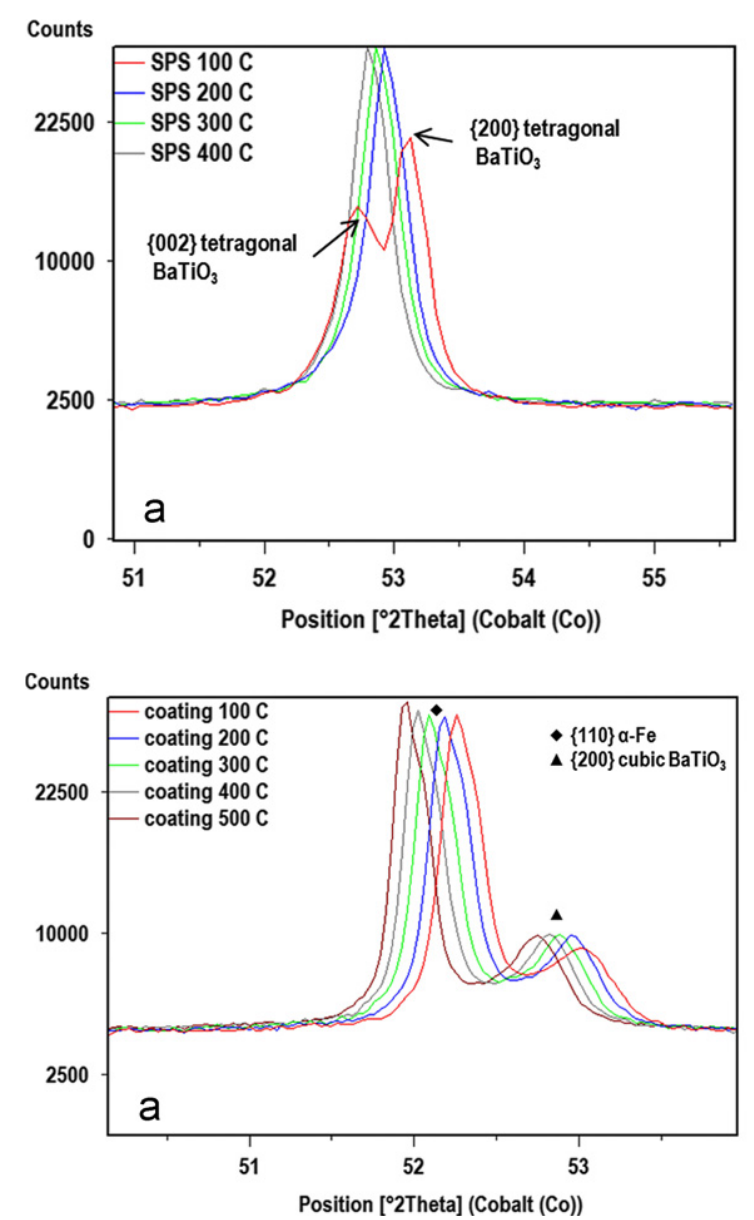

temperature is above room temperature. However a sharp maximum of permittivity indicates that the expected $\mathrm{t}-\mathrm{c}$ transformation absents. Concerning the second transformation, theoretically at $+5^{\circ} \mathrm{C}$, there is also not a sharp change of permittivity.

The measured loss factor for the GSP coating was about 0.3 (for $1 \mathrm{kHz}$ ) below room temperature and increases with temperature to 0.9 at $200{ }^{\circ} \mathrm{C}$. This value is rather high.

The relative permittivity of the SPS sample (Fig. 6) is higher and also the loss factor (Fig. 7) is lower for the sample measured in the sintering pressure direction than for those measured in the perpendicular direction.

The volume resistivity of GSP coating is $74.8 \pm$ $19.6 \mathrm{k} \Omega \mathrm{m}$ at $100 \mathrm{~V} \mathrm{DC}$, but it seems to increase with decreasing voltage. Probably due to the presence of hydrogen species [23], the current-voltage characteristic has a similar character as in the case of amorphous BT [25].

\subsection{Calorimetric response and structural stability}

A comparison of the heating branches of the differential scanning calorimetry of the three samples (feedstock, GSP coating and SPS bulk) is given in Fig. 8. The feedstock powder has an endothermic peak at $+15^{\circ} \mathrm{C}$ and a second
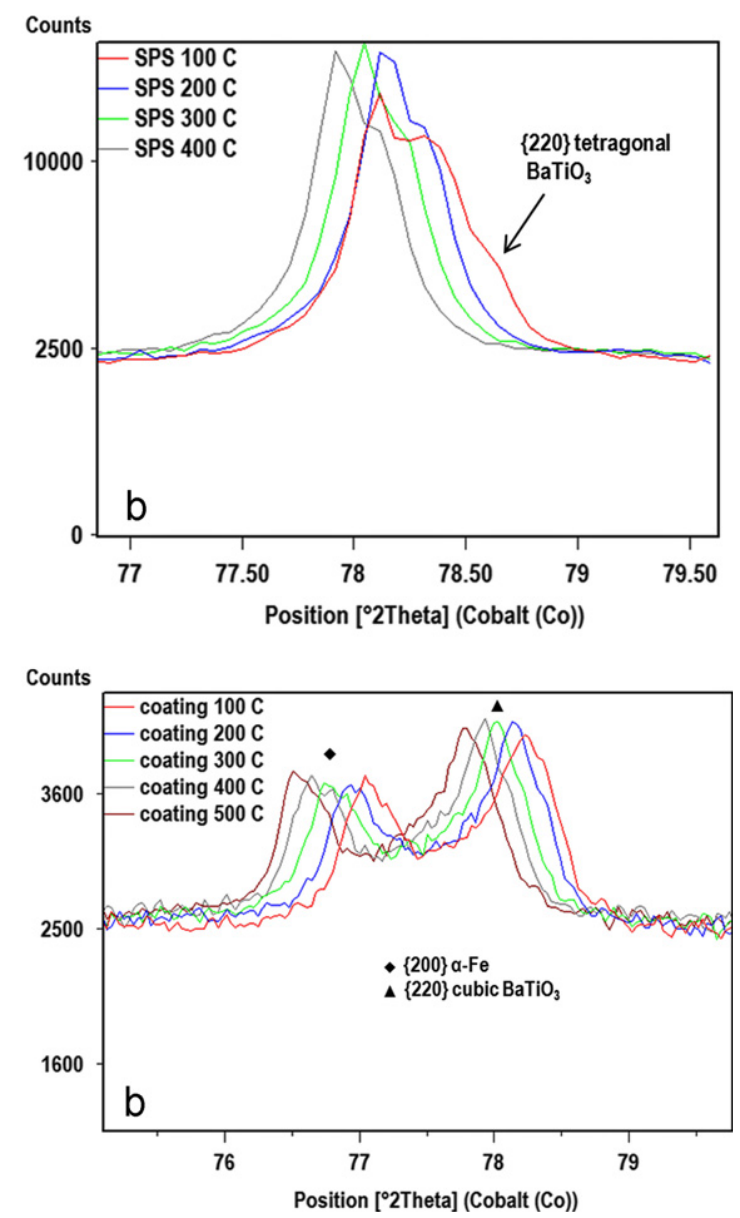

Fig. 4. Temperature-resolved X-ray diffraction of the SPS and plasma sprayed BT samples. The $Y$-axis is square-root-scaled. 


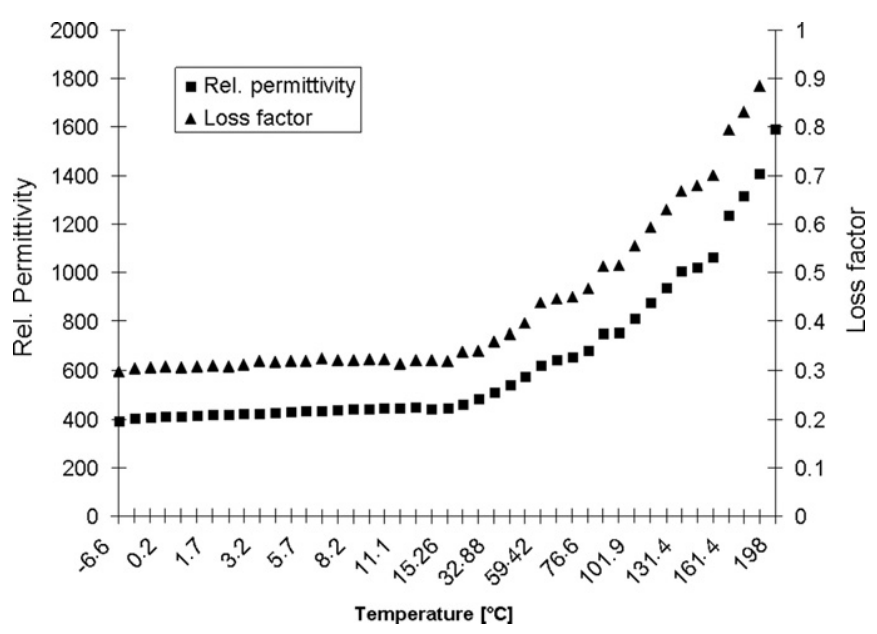

Fig. 5. Dependence of permittivity and loss factor of the plasma sprayed BT coating on temperature at $1 \mathrm{kHz}$.

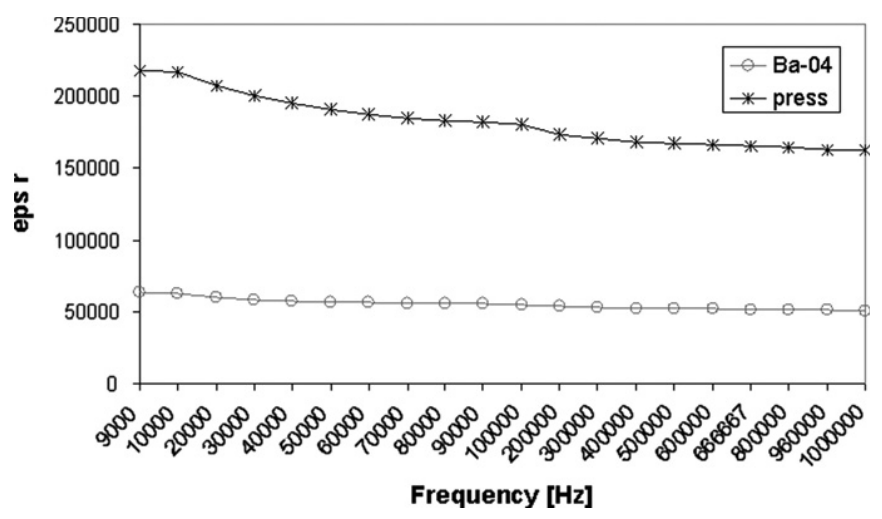

Fig. 6. Frequency dependence of relative permittivity of the SPS sample parallel with the sintering pressure (labeled "press") and perpendicular to the sintering pressure.

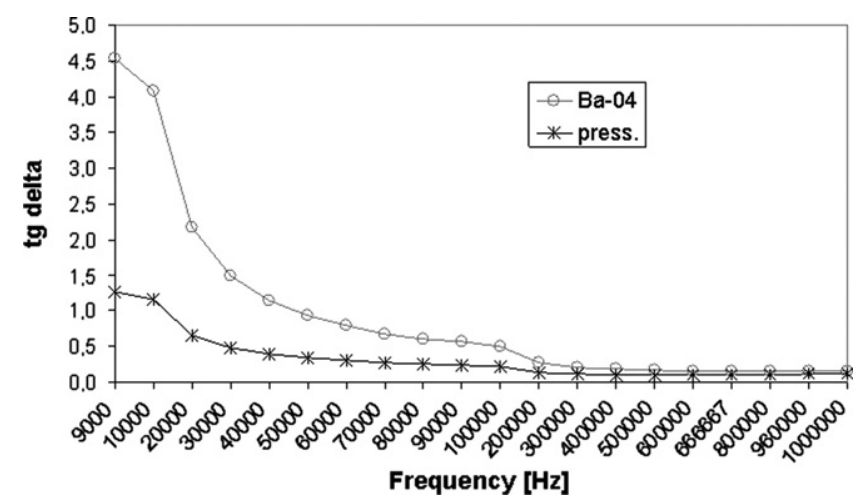

Fig. 7. Frequency dependence of the loss tangent of the SPS sample parallel with the sintering pressure (labeled "press") and perpendicular to the sintering pressure.

one at $+129^{\circ} \mathrm{C}$. The SPS bulk has the same transformations at $+6{ }^{\circ} \mathrm{C}$ and $+115^{\circ} \mathrm{C}$, respectively. These peaks are depicted in detail in Fig. 9. The orthorombic to tetragonal (o-t) phase transformation is shifted of about $9{ }^{\circ} \mathrm{C}$ whereas

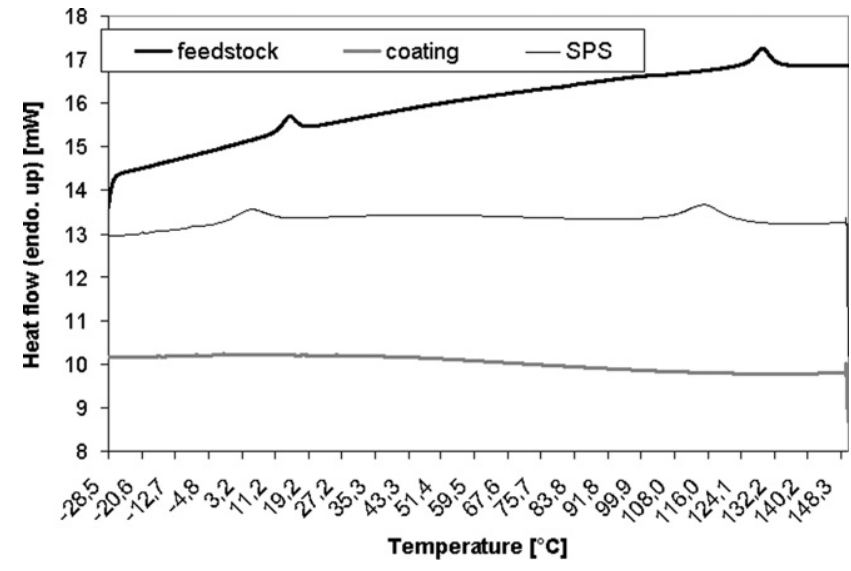

Fig. 8. Differential scanning calorimetry of three samples.

the tetragonal to cubic $(\mathrm{t}-\mathrm{c})$ is shifted of about $14{ }^{\circ} \mathrm{C}$, in both cases the SPS bulk transforms at a lower temperature. During spark plasma sintering, it may exist as a gradient of temperature (which is normally relatively small) within the sample and this could contribute to the presence of local inhomogeneities [26].

\section{Discussion}

\subsection{Resonant ultrasound spectroscopy}

The RUS results obtained for the SPS material are in satisfactory agreement with the temperature dependencies of Young's modulus and the mechanical loss determined for conventionally sintered $\mathrm{BaTiO}_{3}$ by Cheng et al. [27,28] using mechanical spectroscopy at frequencies about $3 \mathrm{kHz}$. Cheng et al. did, however, observe a much sharper slope change for Young's modulus at the orthorhombicto-tetragonal transition temperature and even a discontinuity jump at the tetragonal-to-cubic transition temperature (and also some additional damping peaks attributed to relaxation processes in large grains.) Our RUS results are rather similar to the behavior of $\mathrm{BaTiO}_{3}$ doped by $2 \%$ of $\mathrm{Nb}$ reported also in the papers of Cheng et al. $[27,28]$. It is probable that the SPS processing induces in the material some specific microstructure, which has a similar effect on the mechanical properties as does the doping.

For completeness, let us mention here that our RUS measurements did not detect any anomalous softening close to the tetragonal-to-cubic transition, as reported by Dong et al. [29], who used mechanical spectroscopy at very low frequencies $(0.1$ to $10 \mathrm{~Hz})$ and very fine temperature steps.

Concerning the RUS results of the GSP sample, the linking between the damping peak at $+85^{\circ} \mathrm{C}$ and the ferroelectric transition is highly questionable. The ferroelectric phase contains mobile domain walls which interact with the mechanical vibrations [30], the para-toferroelectric transition should, thus, lead to an increase of damping (as for the SPS material or for the con- 

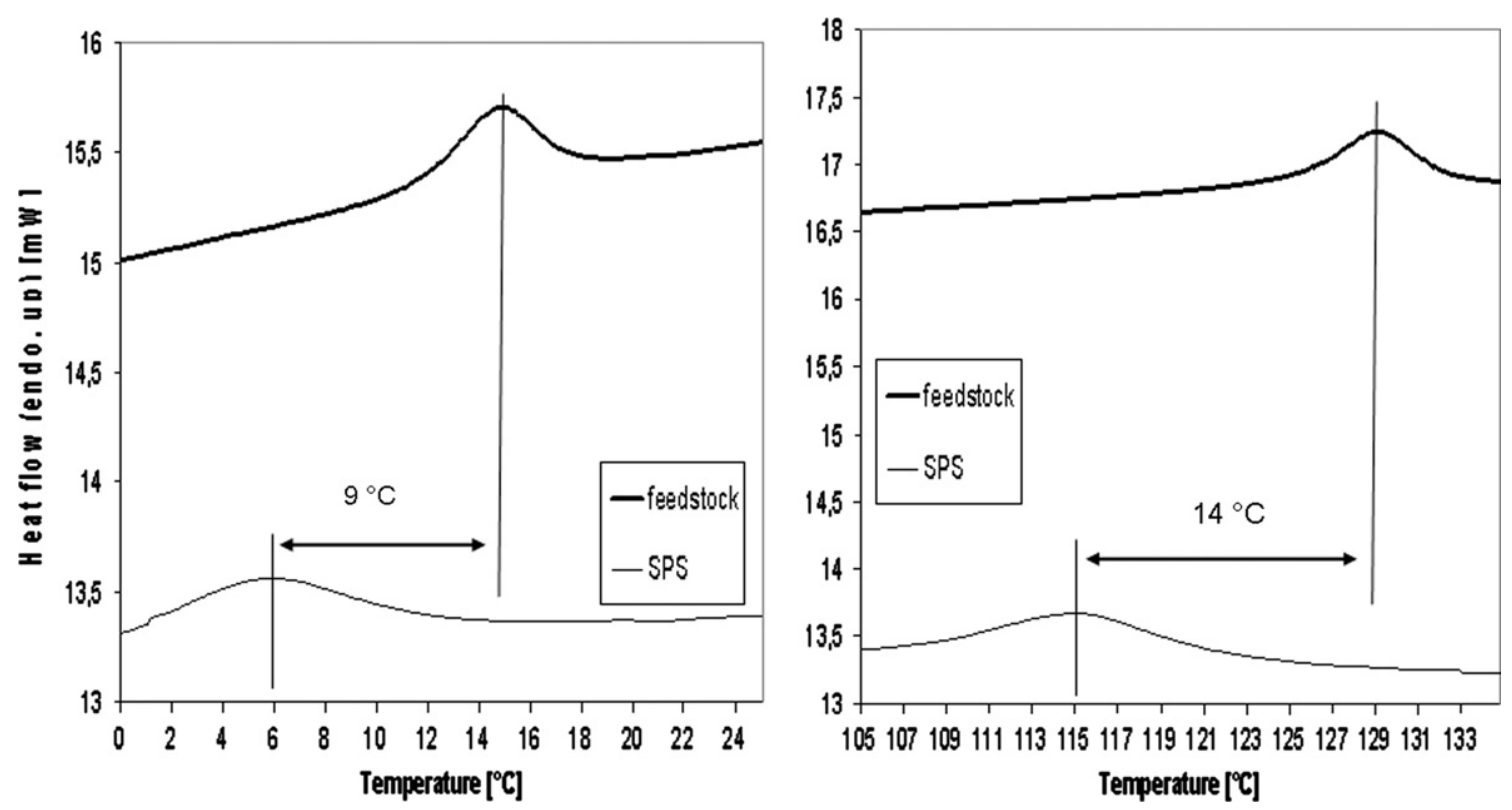

Fig. 9. Details of the DSC curves of the feedstock and SPS bulk around the transformation temperatures.

ventionally sintered $\left.\mathrm{BaTiO}_{3}[27,28]\right)$. Hence, it is more plausible that the damping peak at $+85^{\circ} \mathrm{C}$ corresponds rather to some inelastic dissipative mechanism of the microstructure (e.g. microstructural sliding [31]), which has no relation to the structural phase transitions inside the splats. Nevertheless, this peak exhibits no hysteresis and is fully reproducible with repetitions of the thermal cycle.

The only evidence of a possible ferroelectric transition in the GSP material is the fact that the $f(T)$ curve is not strictly convex/concave, but has an inflection point at approximately $+80{ }^{\circ} \mathrm{C}$.

On the other hand, a hysteretic loop can be observed between $+5{ }^{\circ} \mathrm{C}$ and $-40{ }^{\circ} \mathrm{C}$. This indicates that some structural transition takes place in the GSP material, although at significantly lower temperatures that any of the two transitions observed for the SPS material. During the heating run, the reverse transition is, moreover, accompanied by a small damping peak (see the zoomed area in Fig. 3).

\subsection{Phase analysis by XRD}

Well separated $\{002\}$ and $\{200\}$ XRD peaks of the SPS sample pattern (Fig. 4) are a characteristic sign of the tetragonal structure. The tetragonal BT phase was the single constituent of the feedstock powder [23]. The intensity ratio of individual peaks of the feedstock as well as of the coatings is very similar to patterns reported in the literature [24].

In the structure of the GSP coating probably the tetragonality exists but the $c / a$ ratio is so close to 1 that the XRD technique is able to identify the crystal lattice only as cubic.

\subsection{Structural consequences of the behavior in the electric field}

We suggest that for the GSP coating microstructural imperfections along the splat boundaries are responsible for the character of permittivity and loss factor response to the temperature changes.

Various papers deal with an effect of the hydrogen-rich atmosphere onto $\mathrm{BaTiO}_{3}$ during its synthesis or subsequent annealing. An interstitial $\mathrm{H}$ atom was found to bind to one of the $\mathrm{O}$ atoms of $\mathrm{BaTiO}_{3}$ structure forming an $\mathrm{OH}$ group [32]. Such a defect in the $\mathrm{BaTiO}_{3}$ structure contributes to a decrease of resistivity as well as a marked rise of the loss tangent because the material starts to behave like an n-type semiconductor [33]. This is because in such defective cells $\mathrm{Ti}^{4+}$ is reduced to $\mathrm{Ti}^{3+}$ [34]. Hydrogen incorporation in barium titanate films during the deposition process can contribute to the transport phenomena by introducing several features. At temperatures higher than $-30{ }^{\circ} \mathrm{C}$ protons (from hydrogen) contribute to the conduction mechanism as mobile ionic species [33]. The sign of this effect of mobile ions in our GSP sample is the hysteretic loop formed on RUS curves approximately in the range $-40{ }^{\circ} \mathrm{C}$ to $0{ }^{\circ} \mathrm{C}$ (Fig. 3). In addition, protons have been proposed to induce n-type conductivity by generating shallow donor levels within the bandgap in titanates [33]. We suggest that reaction of $\mathrm{BaTiO}_{3}$ with hydrogen ions in plasma can follow the principles expressed in Ref. [35]: $\quad \mathrm{BaTiO}_{3}+2 \mathrm{H}^{+}=\mathrm{Ba}^{2+}+\mathrm{TiO}_{2}$ (rutile) $+\mathrm{H}_{2} \mathrm{O}$.

Concerning the tetragonal to cubic $(\mathrm{t}-\mathrm{c})$ phase transition and its influence on relative permittivity $\varepsilon_{\mathrm{r}}$, it is possible to find in the literature very contradictory statements. Sometimes the tetragonal phase is reported to have $\varepsilon_{\mathrm{r}}$ higher than the cubic phase [36,37], while in other works $[38,39]$ 
an opposite opinion is expressed. Also the well known fact that the maximum of $\varepsilon_{\mathrm{r}}$ lies exactly at the transformation temperature $[7,40]$ is reported with a variety of modifications. Several works have shown this maximum as very sharp [7,39], elsewhere is it presented as rather flat [36].

The values of $\varepsilon_{\mathrm{r}}$ are connected with the grain size $[40,41]$ of $\mathrm{BaTiO}_{3}$, which is at bulk fabrication processes associated with the size of the initial powders. For the grain sizes comparable with the splat thickness at plasma spraying (e.g., 2-5 $\mu \mathrm{m}$ ) the most frequently reported values of $\varepsilon_{\mathrm{r}}$ are about $1000-1500[7,39,40,42,43]$. The frequency for which this $\varepsilon_{\mathrm{r}}$ was obtained is seldom indicated in the literature [39]. In the cited work of Zhan et al. [39], $\varepsilon_{\mathrm{r}}$ is approximately 1000 at $1 \mathrm{kHz}$.

Concerning the SPS sample, the difference in both observed sample orientations is most probably associated with a certain anisotropy of the porosity that should mean better grain-to-grain contact and therefore denser structure with easier polarization. Detailed microstructural investigation of this sample was however not performed. The detected "colossal permittivity" [3] values (over 200,000), elsewhere called "supercapacitor features" [10], are in agreement with our results.

The electric resistivity values of the GSP coatings $(74.8 \pm 19.6 \mathrm{k} \Omega \mathrm{m}$, see the paragraph 3.3$)$ are relatively low (see the discussion above, where the Reference [33] is mentioned in connection with the n-type semiconductor). The volume resistivity of one selected SPS BT sample is 50 $\mathrm{k} \Omega \mathrm{m}$ at $100 \mathrm{~V}$. The slightly higher value for the coating is logical taking into account its less homogeneous microstructure (see Fig. 8). In the plasma sprayed sample (Fig. 10a) the pores and vertical cracks partially block a distribution of the charge (and make so the resistive environment). In contrast the SPS sample structure (Fig. 10b) exhibit with fine grains having relatively uniform size and pores only on several grain boundaries.

\subsection{Combination of the techniques used}

Let us mention here that the transition temperatures detected by DSC for the SPS material are slightly shifted from those obtained from RUS (approximately $+5{ }^{\circ} \mathrm{C}$ for the tetragonal-to-cubic transition and $+12{ }^{\circ} \mathrm{C}$ for the orthorhombic-to-tetragonal transition). However, the temperature intervals within which the slopes of the RUS curves change are relatively broad (especially for the orthorhombic-to-tetragonal transition). That is because the individual grains transform under slightly different conditions each other, and it is not fully justified to assume that the points of maximal change of the slope should necessarily correspond to the maximal change in the volume fractions of the individual phases, i.e., to the maximum of the DSC peak. Similarly, there is no DSC peak observed at low temperatures for the GSP coating, although there is an obvious hysteretic loop on the RUS curve. In this case, the possible interpretation is that the RUS measurements can detect the changes of mechanical
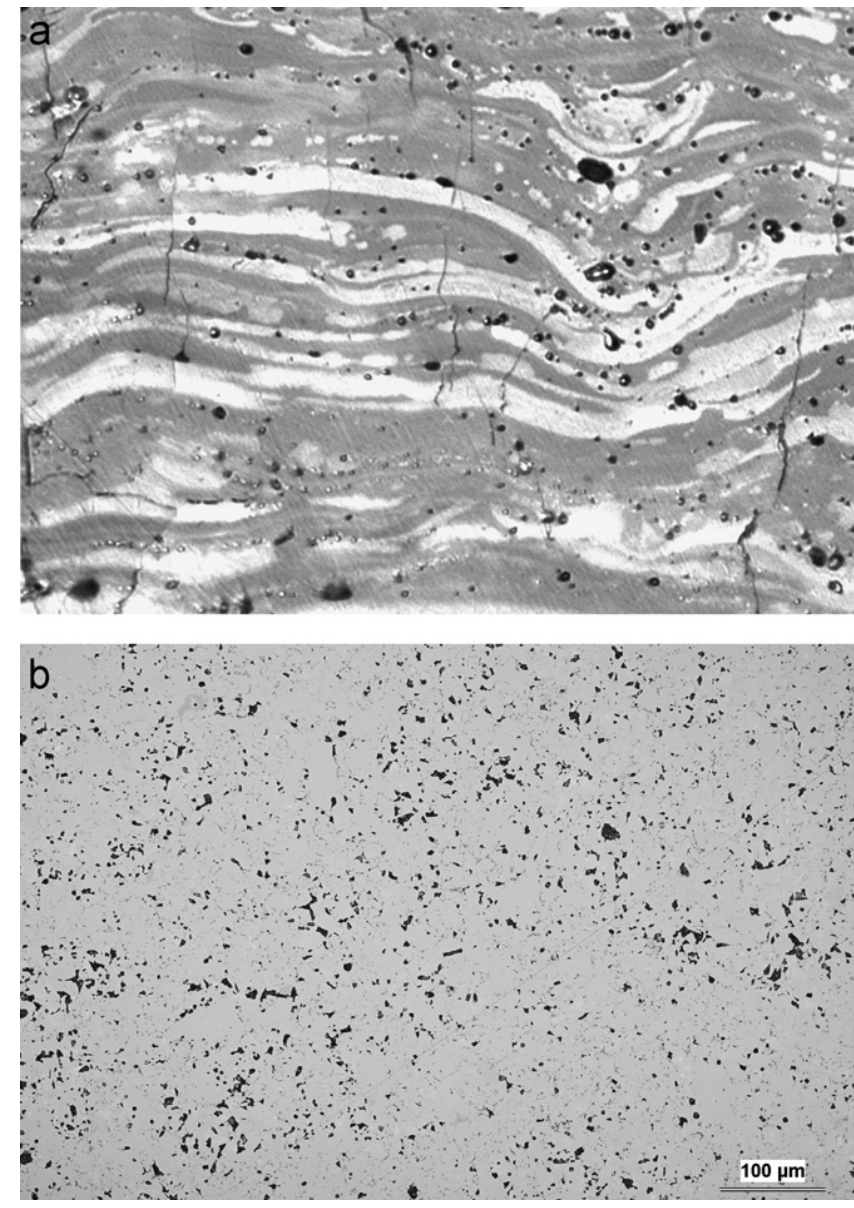

Fig. 10. Cross section of the BT coating (a) and SPS bulk (b) - light microscopy; both with the same scale.

properties in relatively small volume fractions (RUS can be used, e.g., to detect elasticity of surface layers the volume of which is less than $1 / 100$ of the volume of the underlying substrate [44]), which, however, do not produce/consume sufficient latent heat to be detectable by DSC.

Concerning the spark plasma sintering process, for the equivalent constant DC current [45] $1 \mathrm{kA}$, which we used, the radial temperature difference in a non-conductive sample can be of about $60-80{ }^{\circ} \mathrm{C}$ between the center and the cylinder wall [46]. The heat lost by radiation toward the wall chambers controls both the thermal and stress gradients [47]. At the high temperature used, the radial and angular stresses, which are much higher than the vertical applied stress, [47] provide the more significant contribution to the stress-related driving force for densification during the SPS treatment. Consequently the thermal history of the SPS sample is not as uniform as usually considered.

On the calorimetric response of the GSP BT coating sample no detectable event was observed within the entire temperature range. The change in $\mathrm{BaTiO}_{3}$ unit cell symmetry at a phase transition is connected with the shift of the $\mathrm{Ba}$ atom from the center of the cube into a new stable position during the phase transition. Six various equivalent 
shifts are possible. The physical cause of such a transition originates from the temperature dependence of the energy of oscillations of the $\mathrm{Ba}$ ion. At the temperature of the phase transition, this energy is practically zero and the atom is completely free in the directions of the main cubic axes. Consequently, the material exhibits an anomaly in the permittivity value. A very weak electric field suffices to shift the freed atom from its original position at this energetic state [48]. The combination of core-shell grains and increased internal stress resulted in an essentially flat permittivity response on a changing temperature. As a consequence of the rapid cooling and the reducing conditions a microstructure inducing a space charge layer effect was reported [49]. This space charge is responsible for high losses and for the strong frequency dispersion of relative permittivity [48].

In the case of plasma sprayed $\mathrm{BaTiO}_{3}$, due to internal stress - a consequence of rapid cooling — the lattice is limited in providing the energy of an oscillating $\mathrm{Ba}$ atom and to distribute it in the entire volume of the material. This is why a temperature of zero energy of oscillations does not exist, and a temperature evolution of permittivity is without peaks. The electric field necessary for a shift of the $\mathrm{Ba}$ atoms is correspondingly higher. By analogy, the shift from cubic-to-tetragonal symmetry is hindered resulting in the $c / a$ ratio being close to 1 , hence, the $\mathrm{X}$-ray patterns of plasma sprayed coating below $+120{ }^{\circ} \mathrm{C}$ do not resemble those observed in SPS sample.

\section{Conclusions}

All tests used - resonant ultrasound spectroscopy, dielectric measurements, differential scanning calorimetry and temperature-resolved X-ray diffraction - indicated an absence of the tetragonal-to-cubic $(\mathrm{t}-\mathrm{c})$ transformation in the usual temperature range for plasma sprayed GSP coatings.

The results have confirmed that the GSP coating has a significantly broader temperature range of stability of the phase existing at room temperature than all bulk $\mathrm{BaTiO}_{3}$ materials reported in the literature so far. This phase remains stable at least till $-30{ }^{\circ} \mathrm{C}$ during cooling (as approved by DSC and RUS measurements) and at least up to $+175^{\circ} \mathrm{C}$ during heating (this was proved by temperature-resolved X-ray measurements). The phase existing at room temperature was identified as cubic by $\mathrm{XRD}$, probably because of its very small tetragonality, under the detection limit of XRD. This raises the question as to whether the plasma spraying of $\mathrm{BaTiO}_{3}$ might not be a promising tool for preparation of lead-free ferroelectric ceramic materials with similarly enhanced piezoelectric properties as the epitaxial films have.

We have found anisotropy in dielectric measurements for the sample prepared by SPS. The detected "colossal permittivity" or "supercapacitor features" of the $\mathrm{SPS} \mathrm{BaTiO}_{3}$ will need additional verification, mainly from the viewpoint of the stability of voltage-current characteristics.
Although the loss factor values of the GSP samples for low frequencies are rather high due to the microstructural imperfections, the observed broadening of the temperature range of structural stability, together with the fact that GSP spraying is a relatively inexpensive and flexible technique, makes the investigation of this phenomenon attractive. Challenging is also the outlook for possible future technical applications. The GSP sprayed BT coating with permittivity values between 400 and 1600 , without any sharp changes around the transformation temperatures, can find applications in electric circuits and sensors [50].

\section{Acknowledgments}

This work has been financially supported by Czech Science Foundation (Project no. 101/09/0702). The authors wish to thank H. Ageorges (Limoges) for her assistance with plasma spraying and M. Dopita (Freiberg) for his assistance with spark plasma sintering.

\section{References}

[1] Z.-Y. Shen, J.-F. Li, Enhancement of piezoelectric constant $d_{33}$ in $\mathrm{BaTiO}_{3}$ ceramics due to nano-domain structure, Journal of the Ceramic Society of Japan 118 (10) (2010) 940-943.

[2] M.H. Zhao, D.A. Bonnell, J.M. Vohs, Effect of ferroelectric polarization on the adsorption and reaction of ethanol on $\mathrm{BaTiO}_{3}$, Surface Science 602 (2008) 2849-2855.

[3] Z. Valdez-Nava, S. Guillemet-Fritsch, Ch. Tenailleau, T. Lebey, B. Durand, J.Y. Chane-Ching, Colossal dielectric permittivity of $\mathrm{BaTiO}_{3}$-based nanocrystalline ceramics sintered by spark plasma sintering, Journal of Electroceramics 22 (2009) 238-244.

[4] R. Waser, Modeling of electroceramics - applications and prospects, Journal of the European Ceramic Society 19 (1999) 655-664.

[5] P. Ctibor, J. Sedlacek, K. Neufuss, P. Chraska, Dielectric relaxation in calcium titanate-containing ceramics prepared by plasma spraying, Ceramics International 29 (2003) 955-960.

[6] A.H. Dent, A. Patel, J. Gutleber, E. Tormey, S. Sampath, H. Herman, High velocity oxy-fuel and plasma deposition of $\mathrm{BaTiO}_{3}$ and $(\mathrm{Ba}, \mathrm{Sr}) \mathrm{TiO}_{3}$, Materials Science and Engineering B 87 (2001) 23-30.

[7] R.C. Buchanan, Ceramic materials foe electronics, 3rd edition, M. Dekker, New York, USA, 2004.

[8] B. Li, X. Wang, L. Li, H. Zhou, X. Liu, X. Han, Y. Zhang, X. Qi, $X$. Deng, Dielectric properties of fine-grained $\mathrm{BaTiO}_{3}$ prepared by spark-plasma-sintering, Materials Chemistry and Physics 83 (2004) 23-28.

[9] M. Dopita, C.R. Sriram, D. Chmelik, A. Salomon, H.J. Seifert, Spark plasma sintering of nanocrystalline binderless WC hard metals, in: Proceedings of the Conference Nanocon, Olomouc, Czech Republic, 2010.

[10] U.-C. Chung, C. Elissalde, S. Mornet, M. Maglione, Controlling internal barrier in low loss $\mathrm{BaTiO}_{3}$ supercapacitors, Applied Physics Letters 94 (7) (2009) 02903-1072903-5.

[11] D. Sun, X. Ren, K. Otsuka, Stabilization effect in ferroelectric materials during aging in ferroelectric state, Applied Physics Letters 87 (2005) 142903-1-142903-3.

[12] T. Piasecki, K. Nitsch, R. Pazik, W. Strek, Nanopowder grain size effect on the ac electric properties of $\mathrm{Eu}$ doped $\mathrm{BaTiO}_{3}$ nanoceramic, Journal of Physics: Conference Series 146 (2009) 012009-1-012009-6.

[13] T. Piasecki, K. Nitsch, Study of sprayed coatings and compound materials by impedance spectroscopy, Surface and Coatings Technology 205 (2010) 1009-1014. 
[14] Y. Yoneda, T. Okabe, K. Sakaue, H. Terauchi, H. Kasatani, K. Deguchi, Structural characterization of $\mathrm{BaTiO} 3$ thin films grown by molecular beam epitaxy, Journal of Applied Physics 83 (1998) 2458-2461.

[15] K.J. Choi, M. Biegalski, Y.L. Li, A. Sharan, J. Schubert, R. Uecker, Enhancement of ferroelectricity in strained $\mathrm{BaTiO}_{3}$ thin films, Science 306 (2004) 1005-1009.

[16] Y.M. Kim, K.H. Baik, K.S. Park, Microstructure evolution and dielectric properties of plasma sprayed $\mathrm{BaTiO}_{3}$ coatings, in: B.R. Marple, M.M. Hyland, Y.C. Lau, C.J. Li, R.S. Lima, G. Montavon (Eds.), Proceedings of the International Thermal Spray Conference, 2009 pp. $547-550$

[17] A. Migliori, J.L. Sarrao, Resonant Ultrasound Spectroscopy: Applications to Physics, Materials Measurements, and Non-Destructive Evaluation, Wiley, New York, 1997, pp. 119-136 (Chapter 8).

[18] R.G. Leisure, F.A. Willis, Resonant ultrasound spectroscopy, Journal of Physics Condensed Matter 9 (1997) 6001-6029.

[19] M. Landa, P. Sedlak, H. Seiner, L. Heller, L. Bicanova, P. Sittner, V. Novak, Modal resonant ultrasound spectroscopy for ferroelastics, Applied Physics A: Materials Science and Processing 96 (2009) 557-567.

[20] P. Sedlak, M. Landa, H. Seiner, L. Bicanova, L. Heller, Non-contact resonant ultrasound spectroscopy for elastic constants measurement, in: Proceedings of the International Symposium on Laser Ultrasonics: Science, Technology and Applications 1, Article no. 34, NDT Database J. Montreal, Canada, 2008, pp. 1-6, available from: 〈www.NDT.net〉

[21] J.I. Pérez-Landazábal, V. Sanchéz-Alarcos, C. Góméz-Polo, V. Recarte, V.A. Chernenko, Vibrational and magnetic behavior of transforming and nontransforming $\mathrm{Ni}-\mathrm{Mn}-\mathrm{Ga}$ alloys, Physical Review B 76 (2007) 092101-1-092101-3.

[22] R.E.A. McKnight, B.J. Kennedy, Q. Zhou, M.A. Carpenter, Elastic anomalies associated with transformation sequences in perovskites: II. The strontium zirconate-titanate $\mathrm{Sr}(\mathrm{Zr}, \mathrm{Ti}) \mathrm{O}_{3}$ solid solution series, Journal of Physics: Condensed Matter 21 (2009) 27-35.

[23] P. Ctibor, H. Ageorges, V. Štengl, N. Murafa, I. Píš, T. Zahoranová, V. Nehasil, Z. Pala, Structure and properties of plasma sprayed $\mathrm{BaTiO}_{3}$ coatings: spray parameters versus structure and photocatalytic activity, Ceramics International 37 (2011) 2561-2567.

[24] X. Wang, L. Zhang, H. Liu, J. Zhai, X. Yao, Dielectric nonlinear properties of $\mathrm{BaTiO}_{3}-\mathrm{CaTiO}_{3}-\mathrm{SrTiO}_{3}$ ceramics near the solubility limit, Materials Chemistry and Physics 112 (2008) 675-678 015902.

[25] R. Thomas, D.C. Dube, M.N. Kamalasanan, N.Deepak Kumar, Electrical properties of sol-gel processed amorphous $\mathrm{BaTiO}_{3}$ thin films, Journal of Sol-Gel Science and Technology 16 (1999) 101-107.

[26] S.W. Wang, L.D. Chen, T. Hirai, Densification of $\mathrm{Al}_{2} \mathrm{O}_{3}$ powder using spark plasma sintering, Journal of Materials Research 15 (4) (2000) 982-987.

[27] B.L. Cheng, M. Gabbay, W. Duffy Jr., G. Fantozzi, Mechanical loss and Young's modulus associated with phase transitions in barium titanate based ceramics, Journal of Materials Science 31 (1996) 4951-4955.

[28] B.L. Cheng, M. Gabbay, G. Fantozzi, W. Duffy Jr., Mechanical loss and elastic modulus associated with phase transitions of barium titanate ceramics, Journal of Alloys and Compounds 211-212 (1994) 352-355.

[29] L. Dong, D.S. Stone, R.S. Lakes, Softening of bulk modulus and negative poisson ratio in barium titanate ceramic near the curie point, Philosophical Magazine Letters 90 (1) (2010) 23-33.

[30] A.V. Turik, E.I. Bondarenko, Effect of domain structure on physical properties of ferroelectrics, Ferroelectrics 7 (1974) 303-305.

[31] P.J. Torvik, A slip damping model for plasma sprayed ceramics, Journal of Applied Mechanics - Transactions of ASME 76 (2009) 061018-1-061018-8.
[32] J. Chimborazo, M. Castillo, C. Velasco, A. Stashans, H atom in $\mathrm{BaTiO}_{3}$ and $\mathrm{CaTiO}_{3}$ crystals: structure, electronic properties, and diffusion, Proceedings of SPIE (Advanced Organic and Inorganic Optical Materials) 5122 (2003) 280.

[33] F. El Kamel, P. Bonin, Proton related defects in $\alpha-\mathrm{BaTiO}_{3}: \mathrm{H}$ films based MIM capacitors, Solid State Ionics 180 (2009) 853-856.

[34] D.C. Sinclair, J.M.S. Skakle, F.D. Morrison, R.I. Smith, T.P. Beales, Structure and electrical properties of oxygen-deficient hexagonal $\mathrm{BaTiO}_{3}$, Journal of Material Chemistry 9 (6) (1999) 1327-1331.

[35] S. Lee, U. Paik, V.A. Hackley, Y.G. Jung, K.J. Yoon, Microstructure and permittivity of sintered $\mathrm{BaTiO}_{3}$ : influence of particle surface chemistry in an aqueous medium, Materials Research Bulletin 39 (2004) 93-102.

[36] J.G. Hyun, S. Lee, S.D. Cho, K.W. Paik, Frequency and temperature dependence of dielectric constant of epoxy $/ \mathrm{BaTiO}_{3}$ composite embedded capacitor films (ECFs) for organic substrate, in: Proceedings of the Electronic Components and Technology Conference, 2005.

[37] M. Valant, A. Dakskobler, M. Ambrozic, T. Kosmac, Giant permittivity phenomena in layered $\mathrm{BaTiO}_{3}-\mathrm{Ni}$ composites, Journal of the European Ceramic Society 26 (2006) 891-896.

[38] M.L. Napijalo, Z. Nikolic, J. Dojcilovic, M.M. Napijalo, L. Novakovic, Temperature dependence of electric permittivity of linear dielectrics with ionic and polar covalent bonds, Journal of Physics and Chemistry of Solids 59 (8) (1998) 1255-1258.

[39] G. Zhan, A.K. Mukerjee, J.D. Kuntz, J. Wan, High Density Barium Titanate of High Permittivity, U.S. Patent no. 6,905,649 B2, 2005.

[40] R.L. Brutchey, G. Cheng, Q. Gu, D.E. Morse, Positive temperature coefficient of resistivity in donor-doped $\mathrm{BaTiO}_{3}$ ceramics derived from nanocrystals synthesized at low temperature, Advanced Materials 20 (2008) 1029-1033.

[41] N. Setter, R. Waser, Electroceramic materials, Acta Materialia 48 (2000) 151-178.

[42] T. Hiramatsu, T. Tamura, N. Wada, H. Tamura, Y. Sakabe, Effects of grain boundary on dielectric properties in fine-grained $\mathrm{BaTiO}_{3}$ ceramics, Materials Science and Engineering B 120 (2005) 55-58.

[43] W.H. Tuan, S.K. Lin, The microstructure-mechanical properties relationships of $\mathrm{BaTiO}_{3}$, Ceramics International 25 (1999) 35-40.

[44] N. Nakamura, H. Ogi, M. Hirao, Elastic constants of chemicalvapor-deposition diamond thin films: resonance ultrasound spectroscopy with laser-doppler interferometry, Acta Materialia 52 (2004) 765-771.

[45] K. Vanmeensel, A. Laptev, J. Hennicke, J. Vleugels, O. Van der Biest, Modeling of the temperature distribution during field assisted sintering, Acta Materialia 53 (2005) 4379-4388.

[46] U. Anselmi-Tamburini, S. Gennari, J.E. Garay, Z.A. Munir, Fundamental investigations on the spark plasma sintering/synthesis process: II. Modeling of current and temperature distributions, Materials Science and Engineering A 394 (2005) 139-148.

[47] G. Antou, M. Gendre, G. Trolliard, A. Maitre, Spark plasma sintering of zirconium carbide and oxycarbide: finite element modeling of current density, temperature, and stress distributions, Journal of Materials Research 24 (2) (2010) 404-412.

[48] A. Koller (Ed.), Structure and Properties of Ceramics, Elsevier, Amsterdam, 1994.

[49] R. Licheri, S. Fadda, R. Orru, G. Cao, V. Buscaglia, Selfpropagating high-temperature synthesis of barium titanate and subsequent densification by spark plasma sintering (SPS), Journal of the European Ceramic Society 27 (2007) 2245-2253.

[50] S. Sampath, Thermal spray applications in electronics and sensors: past, present, and future, Journal of Thermal Spray Technology 19 (5) (2010) 921-949. 